\title{
Examination of the Relationship between Passion, Perfectionism and Burnout in Athletes*
}

\author{
Ebru Demirci ${ }^{1}$, Fatma Çepikkurt ${ }^{2, *}$ \\ ${ }^{1}$ Ondokuz Mayıs Secondary School, Mersin, Turkey \\ ${ }^{2}$ Physical Education and Sport High School, Mersin University, Turkey
}

Copyright $\odot 2018$ by authors, all rights reserved. Authors agree that this article remains permanently open access under the terms of the Creative Commons Attribution License 4.0 International License

\begin{abstract}
This study was carried out with the goal of examining the relationship between athletes' passion and perfectionism levels and athlete burnout, and to determine to what extent passion and perfectionism scores predict burnout experienced by athletes. A total of 267 athletes, located in various parts of Turkey and competing in various branches of sport, participated in the study on a voluntary basis. Of the participants, 65 were women (mean age: $20.12 \pm 3.68$ years) and 202 were men (mean age: $20.2 \pm$ 4.04 years). The data collection tools that employed were the Passion Scale, Sport-Specific Multidimensional Perfectionism Scale, and Athlete Burnout Measure. Descriptive statistics, Pearson Correlation Analysis, and Multiple Linear Regression Analysis were used in the analysis of the data. The results of multiple linear regression analysis conducted to test the predictive effects of athletes' passion and perfectionism scores on burnout scores showed that the perfectionism subdimensions of perceived parental pressure and concern over mistakes were significant predictors of the burnout subdimensions of reduced sense of accomplishment and emotional/physical exhaustion. The analysis further revealed that obsessive passion and the perfectionism subdimensions of perceived parental pressure and concern over mistakes were effective in predicting the burnout subdimension of devaluation. In conclusion, the results of this study indicate that athletes who have developed obsessive passion toward their sport and have perfectionist tendencies that are not harmonizable will be more prone to experience burnout.
\end{abstract}

Keywords Passion, Perfectionism, Burnout, Athlete

\section{Introduction}

The great enthusiasm with which athletic competitions are followed worldwide in recent years demonstrates an increasing interest in sports. The sheer enjoyment of watching, by attracting spectators of high-level matches and competitions, has resulted in athletic performances being followed by even more people. Developments in technology have led to the creation of a sports industry whereby athletes can be enjoyed and watched by the masses anywhere in the world. This situation, in turn, has been a factor in determining athletes' high performance goals. Studies in this field have indicated that technical training undertaken by professional athletes focused purely on performance is not sufficient for them to reach their goals, and that psychological factors should also be investigated with regard to peak performance goals.

In this context, "passion" is a powerful reason for engaging in athletic activity, and one of the most important psychological factors in the athlete's striving for peak. Although the Turkish term tutkunluk ("passion, love, and addiction") is a new concept, the related forms tutku, tutkulu, and tutkun, meaning passion, passionate, and devotee/aficionado, respectively, are frequently used in quotidian life (26). The word "passion", derived from the Latin word "passio", which meant motion, power that overcomes will and judgments, and enthusiasm, has not undergone significant semantic change from the original Latin. The philosophy-based concept of passion, first introduced by Descartes in the book Les Passions de L'Âme (26), is defined as a powerful and lasting feeling directed towards certain objects, persons, or thoughts. As defined psychologically by Vallerand et al. (2003) passion is the inclination of an individual to spend time and energy on what he/she likes (even loves) and considers important (35).

Studies have also shown that the importance people give to activities they enjoy, their internalization, regular participation, and energy and time that they spend on said activities are related to passion. Harmonious passion and obsessive passion are dealt with in the "Two-Dimensional Model of Attachment" (37). According to this model, harmonious passion, defined as autonomous internalization 
resulting from choosing to participate in an activity of one's own volition, free from any external pressure or influence $(35,37)$. If a person participates in an activity independently of external influences, guides the activity him/herself, is happy and experiences positive emotions during or following the activity, then the attitude toward the activity is considered harmonious passion. Conversely, if a person participates in an activity due to external pressures, if the activity guides the person, if he/she is not happy as a result of the activity and/or feels conflicted about it, then that person can be assumed to have developed obsessive passion. According to the model, people with harmonious passion are more flexible and attentive toward the activity and more restrained and less defensive during the activity. Those who develop obsessive passion are firm, tenacious, ego-oriented, experience feelings of guilt when they do not participate, have difficulty focusing, and are anxious $(29,35)$.

The dictionary definition of perfectionism, another variable in the study, is "to view everything less than perfect as unacceptable". Examining perfectionism conceptually for the first time, Hollander (19) defined it as "the practice of demanding of oneself or others a higher quality of performance than is required by the situation", and considered it a negative personality trait. According to Burns (3), a psychiatric researcher who has studied the negative aspects of perfectionism, perfectionists are portrayed as difficult or unreasonable people in the context of achieving the standards they have set, or as people obsessively tied to impossible goals or who measure their value only in terms of productivity and success (3). Burns (3) argued that in such individuals, this drive would make it difficult for them to reach their goals and actually harm their performance.

Examining the literature, perfectionism, which is considered a one-dimensional concept originating from an individual, has been observed over the years to possibly have positive aspects in addition to its negative aspects. Its features, defined as dual by a number of different researchers, are critical for a more detailed examination of the concept of perfectionism. Hamacheck (1978), studying the dual nature of perfectionism as normal and neurotic perfectionism, emerged as the first researcher to contribute to the literature on this particular phenomenon (15). Later, Rice, Ashby, and Slaney (31) divided perfectionism into two categories, harmonious and disharmonious. According to Slade and Owens (32), who classify perfectionism on the basis of its behavioral outcomes, the two types of perfectionism, healthy and unhealthy, depend on the results of the individual's action.

Perfectionism, originally considered a concept in which only individual-originated psychological processes are effective, was later revealed by researchers to be influenced by interpersonal relationships as well. Frost, Marten, Lahart, and Rosenblate (1990), who work in this field, have argued that perfectionism is multidimensional and that family relationships may be influential in guiding an individual's behaviors (12). Hewitt and Flett (1991) carried out studies based on the multidimensional definition of perfectionism and emphasized the importance of the social environment in perfectionism (16). They concluded that perfectionism not only affects interpersonal relationships but is also itself affected by interpersonal relationships.

Burnout, the dependent variable in the present study, is defined as "failure or exhaustion in the face of excessive demands on energy, strength, or resources" (10). The concept of burnout, first studied by Freudenberger in the 1970s, is a consequence of the changes that an intense work pace creates in an individual and others, and has been expressed as a process that affects an individual's productivity (11). In the following years, the concept of burnout was defined by Maslach and Jackson (1981) as a syndrome of physical and mental dimensions involving physical exhaustion, long-term fatigue, and feelings of helplessness and hopelessness, as well as negative attitudes towards work, life, and others (27). In the field of sports psychology, Raedeke and Smith (2001) proposed that burnout is the physical and psychological cost incurred by individuals as a result of prolonged and intensive participation in an activity (30). According to Raedeke and Smith, the concept of burnout consists of three subdimensions. These are: "reduced sense of accomplishment", defined as an individual's negative attitude toward his/her ability to perform effectively with regard to his/her work; "emotional/physical exhaustion", a stress-dependent variable; and "devaluation", in which an individual develops a negative attitude and feelings toward his/her work (30).

According to the theory of negative-training stress response, which proposes that "more training is better, training should start early, and the professional athlete should train year-round", the consequence of focusing on continuous training and winning is overtraining followed by burnout (13). The concepts of overtraining and fatigue, not to be considered separately from burnout, are threats to the athletes' peak performance goals. The concept of overtraining, which represents a short cycle of training lasting several days or weeks, in which athletes are exposed to excessive training at their maximum or near maximum capacity, constitutes one of the causes of exhaustion (13).

Considering the subdimensions of passivity and perfectionism, dimensions that can be harmonized are expected to negatively predict burnout, while those that cannot be harmonized are thought to positively predict burnout. In a study of 173 young male soccer players, the results of which were similar to our expectations, an attempt was made to explain the predictive role of satisfaction of psychological needs with respect to the relationship between athletes' burnout and their dimensions 
of passion. According to the results of the analysis, the negative relationship between harmonious passion and burnout is explained by the satisfaction of psychological needs at a high level, while a positive relationship was also found between obsessive passion and burnout (6). In another study investigating the effects of discernable stress on the relationship between perfectionism and burnout, the sample group consisted of coaches, who play a principal role in athletics (34). As a result of the study conducted with 177 coaches, perfectionism that could not be harmonized due to discernable stress was revealed to have as much of a direct effect as an indirect effect on burnout. Regarding the the relationship between harmonizable perfectionism and burnout, no direct or indirect effect resulting from discernable stress was found (34).

Presently, achieving the athletic success that requires high performance is possible because, in addition to taking advantage of proper training programs, athletes are mentally and emotionally healthy. "Passion", considered one of the most critical psychological factors in athletics, and "perfectionism" levels, which contribute to athletes' feelings about achieving maximum success, have been found to be important in determining the relationship with "burnout levels", themselves predicted to be a negative factor in reaching goals set in the sports environment. In this context, it is believed that demonstrating the predictive power of the level of passion for sports and the perfectionism of athletes with respect to burnout will represent a meaningful contribution to the literature.

\section{Materials and Methods}

\subsection{Research Model}

This present research is a descriptive study following the relational screening model with the goal of examining the relationship between passion, perfectionism, and burnout in athletes. The relational screening model is a research model that enables determination of the relationship or the degree of relationship between two or more variables (23).

\subsection{Study Group}

A total of 267 athletes, located in various parts of Turkey and competing in various branches of sport (basketball, football, athletics and wrestling) voluntarily participated in the present study; 65 were women (mean age: $20.12 \pm 3.68$ years) and 202 were men (mean age: $20.2 \pm 4.04$ years). The average age for starting sports for the female athletes was $9.41 \pm 4.14$, while the average for male athletes was $8.66 \pm 4.19$. The present study began with 267 participants and was continued with data from 254 athletes following the removal of athlete data that affected normal distribution.

\subsection{Data Collection Tools}

A personal information form, the Passion Scale, Multidimensional Perfectionism Scale for Athletes and Athlete Burnout Measure were used for the athletes participating in this study.

Passion Scale: The passion scale developed by Vallerand et al. (35) has been adapted to Turkish, and validity and reliability studies have been tested on athletes competing on athletic teams in universities located in Ankara, Turkey. The scale, composed of the two subdimensions of harmonious and obsessive passion, consists of 16 items in total, with 6 items each to determine levels of harmonious and obsessive passion, and 4 items to determine the level of passion. The passion scale is a 7-point Likert-type self-assessment scale (35). In the reliability study conducted by Kelecek (25), the internal consistency coefficient of obsessive passion was .78 and that of harmonious passion was .83. The Cronbach alpha values calculated for the present study were .77 and .84 for obsessive passion and harmonious passion, respectively These values indicate that this measuring tool is suitable for use with this sample group. Subscale scores for harmonious and obsessive passion were included in the analysis, and the 4 subitems that measure passion were not taken into consideration.

Multidimensional Perfectionism Scale for Athletes: The sports-specific Multidimensional Perfectionism Scale for Athletes, developed by Dunn, Causgrove-Dunn, and Syrotuik (9) and adapted to Turkish by Çepikkurt (7), was used to determine the athletes' levels of perfectionism. The scale consists of a total of 19 items, with the 3 subdimensions of Concern over mistakes, perceived parental pressure, and personal standards subdimensions. The subscale of Concern over mistakes is comprised of 7 items while personal standards and perceived parental pressure are each evaluated with 6 items. The scale is a 5-point Likert-type self-assessment scale. In the reliability study conducted by Çepikkurt (2011), the internal consistency coefficients for concern over mistakes, personal standards, and perceived parental pressure were $.76, .76$, and .77 , respectively (7). The Cronbach's alpha values calculated for the present study were .80 for concern over mistakes, .78 for personal standards, and .84 for perceived parental pressure. The Cronbach's alpha values obtained indicate that this tool can be used to evaluate the sample group in the current study.

Athlete Burnout Measure: The Athlete Burnout Measure developed by Raedeke and Smith (30) and adapted to Turkish by Kelecek et al. (24) consists of three subdimensions, reduced sense of accomplishment, emotional/physical exhaustion, and devaluation, with 5 items each, for a total of 15 items. The internal consistency coefficients for the 5-point Likert-type scale were .84 for 
reduced sense of accomplishment, .88 for emotional/physical exhaustion, and .87 for devaluation (24). In the present study, the Cronbach's alpha values were .67 for reduced sense of accomplishment, .87 for emotional/physical exhaustion, and .81 for devaluation. The subscale reliability coefficients of the Passion Scale, Sports-Specific Multidimensional Perfectionism Scale, and Athlete Burnout Scale used for data collection in the present study are reliable and highly consistent when the criteria specified by Kalaycı (22) are taken into account.

\subsection{Analysis of Data}

Pearson product-moment correlation analysis was applied to show the relation between the passion, perfectionism, and burnout scores of the athletes participating in the study. Multiple linear regression analysis was employed in order to determine to what extent athletes' passion and perfectionism scores predicted the burnout that they experienced. In the regression analysis, the subscales of passion and perfectionism were independent variables, while the burnout subscales were dependent. The "Enter" method was used for variable selection, with a margin of error of .05 .

\section{Results}

Values for skewness and kurtosis of the data are shown in Table 1, to determine whether the data in the present study are normally distributed.

Examining the values for skewness and kurtosis shown in Table 1, the values are observed to be within the limits of acceptability. Taking into account the criteria that skewness values should fall between +1 and -1 and kurtosis values between +2 and -2 , the values obtained for all subscales are shown to be within the desired range, and the data exhibit normal distribution (20).

Prior to performing multiple linear regression analysis, the data obtained from the sample group was checked to ascertain that the premises of regression analysis were fulfilled (22). The multicollinearity between independent variables from the regression analysis quantities was tested using the Pearson product-moment correlation analysis method. Multiple linear regression analysis was performed after the results of the correlation analysis were obtained.

The results of correlation analysis showing the relationship between the passion and perfectionism subscales, which are independent variables, and burnout subscales, the dependent variables, are presented in Table 2 .

Table 1. Normality Test Results for the sample group participating in the study

\begin{tabular}{|cccccc|}
\hline Scale & $\mathbf{n}$ & $\overline{\mathbf{X}}$ & $\mathbf{S S}$ & Skewness & Kurtosis \\
\hline Harmonious passion & 254 & 5,26 & 1,17 & -.423 & -.456 \\
\hline Obsessive passion & 254 & 4.54 & 1.23 & -.180 & -.400 \\
\hline Concern over mistakes & 254 & 3.02 & .90 & .011 & -.487 \\
\hline Perceived parental pressure & 254 & 3.25 & 1.05 & -.155 & -.866 \\
\hline Personal standards & 254 & 3.83 & .84 & -.602 & -.314 \\
\hline Reduced sense of accomplishment & 254 & 2.93 & .85 & .374 & .063 \\
\hline Emotional/physical exhaustion & 254 & 2.65 & 1.01 & .566 & -.379 \\
\hline Devaluation & 254 & 2.29 & 1.08 & .700 & -.304 \\
\hline
\end{tabular}

Table 2. Pearson Product-Moment Correlation Analysis Results Concerning the Relationship between the Scores from the Passion and Sports-specific Multidimensional Perfectionism and Athlete Burnout Scales

\begin{tabular}{|c|c|c|c|c|c|c|c|c|}
\hline Variables & HP & OP & COM & PPP & PS & RSA & EPE & D \\
\hline Harmonious Passion (HP) & & & & & & & & \\
\hline Obsessive Passion (OP) & $.615^{* *}$ & & & & & & & \\
\hline $\begin{array}{c}\text { Concern Over Mistakes } \\
\text { (COM) }\end{array}$ & -.062 & $.132^{* *}$ & & & & & & \\
\hline $\begin{array}{c}\text { Perceived Parental Pressure } \\
\text { (PPP) }\end{array}$ & -.001 & .98 & $.531^{* *}$ & & & & & \\
\hline $\begin{array}{c}\text { Personal Standards (PS) } \\
\text { Reduced Sense of } \\
\text { Accomplishment (RSA) }\end{array}$ & $.291^{* *}$ & $.207 * *$ & $.441^{* *}$ & $.531^{* *}$ & & & & \\
\hline $\begin{array}{c}\text { Emotional/ Physical } \\
\text { Exhaustion (EPE) }\end{array}$ & -.002 & $.134^{*}$ & $.324^{* *}$ & $.330^{* *}$ & $.177^{* *}$ & $.627^{* *}$ & & \\
\hline Devaluation (D) & $-.150^{*}$ & .084 & $.316^{* *}$ & $.249^{* *}$ & .002 & $.630^{* *}$ & $.795^{* *}$ & \\
\hline
\end{tabular}

$* p<.05$ 
The results of the analysis revealed that there was a weak but significantly positive correlation between the "harmonious passion" subdimension of the passion scale and the "personal standards" subdimension of the sport-specific multidimensional perfectionism scale $(\mathrm{r}$ $=.29 ; p<.01)$. Similar relationships were observed between the "obsessive passion" subdimension of the passion scale and the "concern over mistakes" and "personal standards" subdimensions of the sport-specific multidimensional perfectionism scale $[(\mathrm{r}=.13 ; p<.05)(\mathrm{r}$ $=.20 ; p<.01)$, respectively]. These findings indicate that there are no multiple links between the independent variables; therefore, regression analysis can be applied to the data obtained from this sample group.

In addition, the results of the correlation analysis showed significant positive correlations between the "reduced sense of accomplishment" subscale of burnout and "concern over mistakes", "perceived parental pressure", and "personal standards" subscales of perfectionism ( $\mathrm{r}$ $=.31, \mathrm{r}=.35, \mathrm{r}=.21$, respectively; all $p<.01$ ). There was a weak but positive relationship $(\mathrm{r}=.13, p<.05)$ between the "emotional/physical exhaustion" subdimension and "obsessive passion". Weak but significantly positive relationships were also found between the burnout subdimension of "emotional/physical exhaustion" and the perfection subscales concern over mistakes", "perceived parental pressure", and "personal standards" $(\mathrm{r}=.32, \mathrm{r}$ $=.33, \mathrm{r}=.18$, respectively; all $p<.05)$. The "devaluation" subdimension of the Athlete Burnout Measure was weakly but negatively associated with "harmonious passion" $(\mathrm{r}=$ $-.15 ; p<.01)$. However, the "devaluation" subdimension was observed to be weakly but positively associated with the perfectionism subdimensions "concern over mistakes" and "perceived parental pressure $(\mathrm{r}=.32, p<.05 ; \mathrm{r}=.25, p$ $<.015$, respectively).

The results of the regression analysis conducted in order to determine the predictive power of passion and perfectionism subscales with respect to scores for the "reduced sense of accomplishment" subscale of burnout are presented in Table 3.

Table 3. Results of Multiple Linear Regression Analysis for the Reduced Sense of Accomplishment Subscale Dependent Variable

\begin{tabular}{|cccc|}
\hline Independent variables & $\beta$ & $\mathrm{T}$ & $\mathrm{p}$ \\
\hline Harmonious passion & .015 & .186 & .853 \\
Obsessive passion & .131 & 1.724 & .086 \\
Concern over mistakes & .149 & 2.000 & .047 \\
Perceived parental pressure & .270 & 3.510 & .001 \\
Personal standards & -.027 & -.361 & .719 \\
\hline $\mathrm{R}=.40, \mathrm{R}^{2}=.14, \mathrm{~F}=9.40$, & $p<.05$, Durbin Watson $=2.018$ \\
\hline
\end{tabular}

Harmonious passion, obsessive passion, and personal standards, included in the analysis as independent variables, were observed to have no predictive effect on the "reduced sense of accomplishment" subscale scores for burnout, a dependent variable. However, "perceived parental pressure" $(\beta=.270)$ and "Concern over mistakes" $(\beta=.149)$ subdimensions, which are independent variables in the analysis, were significantly predictive of "reduced sense of accomplishment" $\left(\mathrm{R}^{2}=.14\right)$. This finding indicates that $14 \%$ of the scores of the "reduced sense of accomplishment" variable can be explained by perceived parental pressure and Concern over mistakes, and that the most important predictor in the model is perceived parental pressure $(\beta$ $=.270$ ).

The results of the regression analysis conducted to determine the "emotional/physical exhaustion" subscale scores of burnout and perfectionism subscales are presented in Table 4.

Table 4. Results of Multiple Linear Regression Analysis for the Emotional/Physical Exhaustion Subscale Dependent Variable

\begin{tabular}{|cccc|}
\hline Independent variables & $\beta$ & $\mathrm{T}$ & $\mathrm{p}$ \\
\hline Harmonious Passion & -.059 & -.0729 & .467 \\
Obsessive Passion & .130 & 1.706 & .089 \\
$\begin{array}{c}\text { Concern over mistakes } \\
\text { Perceived parental } \\
\text { pressure }\end{array}$ & .189 & 2.527 & $.012^{*}$ \\
$\begin{array}{c}\text { Personal Standards } \\
\mathrm{R}=.385, \quad \mathrm{R}^{2}=.131 \quad \mathrm{~F}=8.635\end{array}$ & $\begin{array}{c}\text { p } \\
\text { Durbin Watson }=1.995\end{array}$ & $.003 *$ \\
\hline
\end{tabular}

Harmonious passion, obsessive passion, and personal standards, all independent variables in the analysis, did not reach levels of significance in predicting the "emotional/physical exhaustion" subscale scores for burnout, a dependent variable. The independent variables "perceived parental pressure" $(\beta=.231)$ and "concern over mistakes" $(\beta=.189)$, however, were significantly predictive of the "emotional/physical exhaustion" subdimension of the Athlete Burnout Measure $\left(\mathrm{R}^{2}=.13\right)$. This finding indicates that $13 \%$ of the scores of the "emotional/physical exhaustion" variable can be explained by perceived parental pressure and concern over mistakes, and that the most important predictor in the model is again perceived parental pressure $(\beta=.231)$.

The results of the regression analysis conducted in order to determine the power to predict the "devaluation" subscale scores of exhaustion and perfectionism subscales are presented in Table 5 .

Table 5. Results of Multiple Linear Regression Analysis for the Devaluation Subscale Dependent Variable

\begin{tabular}{|cccc|}
\hline Independent variables & $\mathrm{B}$ & $\mathrm{T}$ & $\mathrm{p}$ \\
\hline Harmonious Passion & -.195 & -2.460 & $.015^{*}$ \\
Obsessive Passion & .191 & 2.536 & $.012^{*}$ \\
Concern over mistakes & .258 & 3.504 & $.001^{*}$ \\
Perceived parental pressure & .186 & 2.443 & $.015^{*}$ \\
Personal Standards & -.193 & -2.572 & $.011^{*}$ \\
\hline $\mathrm{R}=.416 \quad \mathrm{R}^{2}=.16$ & $\mathrm{~F}=10.353$ & $p<.05$ & \\
Durbin Watson $=2.019$ & \\
\hline
\end{tabular}

The independent variables harmonious passion $(\beta=$ 
-195), obsessive passion ( $\beta=.191)$, concern over mistakes $(\beta=.258)$, perceived parental pressure $(\beta=186)$, and personal standards $(\beta=-.193)$ were significant predictors of the Athlete Burnout Measure subdimension "devaluation" $\left(\mathrm{R}^{2}=0.16\right)$. This finding indicates that $16 \%$ of the scores for the "devaluation" variable can be explained by the aforementioned independent variables included in the model, and that the most important predictor in the model is concern over mistakes $(\beta=.258)$. Another noteworthy finding is that the subdimensions of harmonious passion and personal standards are negative predictors of the "devaluation" variable.

\section{Discussion}

Analyzing the results of the athletes' passion and perfectionism scores with regard to predicting burnout, the subscales of perceived parental pressure and concern over mistakes were observed to positively and significantly predict both the "reduced sense of accomplishment" and "emotional/physical exhaustion" subscales. In addition, the subscales of harmonious passion, obsessive passion, and concern over mistakes, perceived parental pressure, and personal standards were important and significant predictors of the "devaluation" subscale of the Athlete Burnout Measure. Another noteworthy finding is that harmonious passion and personal standards are negative predictors of devaluation.

As the research findings indicate, athletes who dwell on their mistakes and feel intense pressure from their family received high scores on all dimensions of the burnout measure. It has always been important to meet the expectations of athletes who expect to be appreciated and approved by their family. The fact that the athlete is trapped between his/her existing potential and the goal set by his/her family can lead to the athlete being drawn into problem-focused psychological effects. In addition to family pressure, overemphasis on mistakes made in competition where the focus was on achieving a goal increases the adversities experienced by athletes. In such cases, an athlete who is compared to other athletes in his/her particular sport by his/her family, who is always expected to be the best and avoid making mistakes, over time begins to feel emotionally and physically inadequate and unsuccessful. The result is that the athlete becomes disappointed because of not meeting his/her expectations, and finally, having become desensitized, experiences burnout.

Reviewing the literature on the relationship between perfectionism and burnout, we find results in agreement with those of the present study. In a study of 202 professional and semi-professional rugby players investigating the relationship between perfectionism and athlete burnout with respect to personal characteristics, a clear parallel was observed (18). In that study, athletes with an elevated sense of perfectionism and frequent experiences with it were found to undergo more intense burnout. In another study, Jowett et al. (21) attempted to determine whether the relationship between perfectionism and burnout could be explained by basic psychological needs. Perfectionist anxieties are negatively associated with athlete responsibility and positively associated with athlete burnout; perfectionist striving, meanwhile, is positively associated with athlete responsibility and negatively associated with athlete burnout. Jowett et al. (21) have taken the role of basic psychological needs into consideration in explaining this relationship between perfectionist anxiety and striving and athlete burnout. In another study whose results support those of the present study, Appleton, Hall, and Hill (2) aimed to examine the mediating role of the relationship between perfectionism and athlete burnout with regard to the goal process and goal achievement orientation. They found a positive relationship between socially imposed perfectionism and burnout dimensions in these studies, and a negative relationship between self-directed perfectionism and burnout dimensions. Findings that non-harmonious dimensions of perfectionism increase burnout in elite athletes support the results of the present study. In their recent meta-analysis, Hill and Curran (17) reviewed 43 studies in the field with the goal of examining the relationship between multidimensional perfectionism and burnout. The results of their meta-analysis found a negative correlation between striving for perfection and burnout, and a significant moderate to high positive correlation between the perfectionism dimension of Concern over mistakes and burnout syndrome. The results of the meta-analysis presented by Hill and Curran (17) are important in supporting the findings obtained in the present study.

Another important finding obtained in the present study is that harmonious passion and obsessive passion scores are effective in predicting devaluation experienced in sports (Table 5). The results of this study also showed that athletes who exhibit harmonious passion for their sport tend to feel less devaluation, while those who develop obsessive passion experience more intense devaluation and emotional/physical exhaustion. The fact that harmonious passion is negatively associated with burnout and obsessive passion is positively associated with burnout conforms to expectations and supports the results of previous studies $(35,4,5,6,14)$. For example, Vallerand et al. (35), in their study of cyclists, found that athletes with high levels of obsessive passion were more likely to quit sports. In another study conducted with 260 athletes, Gustafsson, Hassme'n, and Hassme'n (14) observed that athletes with obsessive passion faced a high risk of burnout and experienced high levels of stress and negative emotions, in agreement with the findings of the current study. In their study of child football players, Curran et al. (5) aimed to reveal the relationship between the dimensions 
of passion and burnout, as well as to test the role of self-determination as a motivational tool in this relationship. In their studies toward this goal, they concluded that harmonious passion is negatively associated with athlete burnout, but that obsessive passion exhibited no correlation with burnout. They also stated that self-regulation plays a critical role in the relationship between harmonious passion and burnout. Curran et al. (6), expanding on the study by Gustafsson et al. (14), aimed to test the mediating role of the pleasure in the relationship between passion and burnout. To that end, in their study on 173 athletes, they found that the pleasure experienced by meeting one's psychological needs mediated the relationship between harmonious passion and burnout, but that it did not mediate the relationship between obsessive passion and burnout. Curran et al. (6) suggested that this finding on the relationship between harmonious passion and burnout can be explained by the great pleasure of satisfying one's psychological needs. In the present study, findings revealing the relationship between passion and burnout and the sample research results presented above indicate that passion has an effect on burnout syndrome experienced by athletes, and especially that obsessive passion will increase emotional exhaustion and devaluation with respect to sports.

\section{Conclusions}

In conclusion, the findings of this study to determine whether athletes' passion and perfectionism scores predict burnout indicate that the negative aspects of perfectionism and burnout increase the burnout experienced in sports, while the positive aspects can delay burnout. This result demonstrates the need to consider the positive and negative aspects of perfectionism and passion separately, as not wholly negative psychological structures. In this context, athletes who develop harmonious passion for their sport and set reasonable personal standards will be less likely to experience burnout syndrome. On the other hand however, for athletes who have developed obsessive passion, focus excessively on their mistakes, and feel pressure from their parents to be successful, burnout syndrome may be unavoidable.

\section{Suggestions}

As perfectionism is not an entirely negative concept, having harmonious dimensions, athletic perfectionism can be studied on the basis of its multifaceted aspects. Different variables which may lead to burnout should be incorporated into future research, considering that athletic burnout has a negative effect on both the athlete and performance. Athletes who experience burnout problems and their families can receive appropriate psychological support, in the light of findings that reveal a strong association between perfectionism and burnout.

\section{REFERENCES}

[1] Açıkgöz A. Mükemmeliyetçilik Dost Sandığınız Düşman (Perfectionism: The Enemy That You Consider a Friend). İstanbul: Kuraldışı Yayıncılık, 2000.

[2] Appleton P R., Hall H K., Hill A P. Relations between multidimensional perfectionism and burnout in junior-elite male athletes. Psychology of Sport and Exercise, 10: 457$465,2009$.

[3] Burns D D., The perfectionist's script for self-defeat. Psychology Today, November: 34-51, 1980.

[4] Carbonneau N., Vallerand R J., Fernet C., Guay F. The role of passion for teaching in intra and interpersonal outcomes. Journal of Educational Psychology, 100, 977-987, 2008.

[5] Curran T., Appleton P R., Hill A P., Hall H K. Passion and burnout in elite junior soccer players: The mediating role of self-determined motivation. Psychology of Sport and Exercise, 12: 655-661, 2011.

[6] Curran T., Appleton P R., Hill A P., Hall H K. The mediating role of psychological need satisfaction in relationships between types of passion for sport and athlete burnout. Journal of Sports Sciences, 31 (6), 597-606, 2013.

[7] Çepikkurt F. Üniversiteli hentbolcuların mükemmeliyetçilik ve kaygı düzeyleri ile başarı hedefleri ve müsabaka sonuçlarına yaptıkları yükleme biçimleri arasındaki ilişkinin incelenmesi (Examination of the relationship between perfectionism and anxiety levels of university handball players and their achievement goals and how they view their match results). Yayınlanmış Doktora Tezi, Çukurova Üniversitesi Sağlık Bilimleri Enstitüsü, Adana. 2011.

[8] Dale J L., Weinberg R. Burnout in sport: A review and critique. Applied Sport Psychology, 2: 67-83, 1990.

[9] Dunn J G H., Causgrove-Dunn J., Syrotuik D G. Relationship between multidimensional perfectionism and goal orientations in sport. Journal of Sport and Exercise Psychology, 24: 376-395, 2002.

[10] Eklund R C., Cresswell S L. Athlete burnout. In G. Tenenbaum, R C, Eklund (Eds.), Handbook of Sport Psychology (3rd ed., pp. 621-641). Hoboken, NJ: Wiley. 2007.

[11] Freudenberger H J., Staff burnout. Journal of Social Issues, 30: 159-165, 1974.

[12] Frost R O., Marten P., Lahart C., Rosenblate R. The dimensions of perfectionism. Cognitive Therapy and Research, 14: 449-468, 1990.

[13] Gould D., Weinberg R S. Foundations of sport and exercise psychology, Sixth edition. Champaign, IL: Human Kinetics. 2015.

[14] Gustafsson H., Hassme'n P., Hassme'n N. Are athletes 
burning out with passion? European Journal of Sport Science, 12: 387-395, 2011.

[15] Hamachek D E. Psychodynamics of normal and neurotic perfectionism. Psychology, 15: 27-33, 1978.

[16] Hewitt P L., Flett G L. Perfectionism in the self and social contexts: Conceptualization, assessment, and association with psychopathology. Journal of Personality and Social Psychology, 60: 456-470, 1991.

[17] Hill A., Curran T. Multidimensional Perfectionism and Burnout. Personality \& Social Psychology Review, 20 (3): 269-288, 2016.

[18] Hill A P., Appleton P R. The predictive ability of the frequency of perfectionistic cognitions, self-oriented perfectionism, and socially prescribed perfectionism in relation to symptoms of burnout in youth rugby players. Journal of Sports Sciences, 29(7): 695-703, 2011.

[19] Hollander M H. Perfectionism. Comprehensive Psychiatry, 6: 94-103, 1965.

[20] Huck S W. Reading statistics and research (5th edition). New York: Addison Wesley Longman, 2008.

[21] Jowett G E., Hill A P., Hall H K., Curran T. Perfectionism and junior athlete burnout: The mediating role of autonomous and controlled motivation. Sport, Exercise, and Performance Psychology, 1: 48-61, 2013.

[22] Kalaycı Ş. SPSS Uygulamalı Çok Değişkenli İstatistik Teknikleri (99-405). Asil Yayınları, Ankara. 2014.

[23] Karasar N. Bilimsel Araştırma Yöntemleri (Scientific Research Methods). Nobel Yayın Dağıtım: Ankara. 2009.

[24] Kelecek S., Kara F M., Kazak Çetinkalp Z., Aşçı F H. Sporcu Tükenmişlik Ölçeği"nin Türkçe Uyarlaması (Turkish Adaptation of the Athlete Burnout Scale). Hacettepe Journal of Sport Sciences, 27 (4): 149-161, 2016.

[25] Kelecek S. Sporcuların Tutkunluk Düzeylerinin; Optimal Performans Duygu Durumu, Güdüsel Yönelim ve Hedef Yönelimini Belirlemedeki Rolü (The Role of Athletes' Attitudes in Determining Emotional State, Motivational Orientation, and Goal Orientation for Optimal Performance). Başkent Üniversitesi, Sağlık Bilimleri Enstitüsü, Egzersiz ve Performans Anabilim Dalı, 2013.
[26] Köknel Ö. Kaygıdan Mutluluğa Kișilik (Personality from Anxiety to Happiness). İstanbul: Altın Kitaplar Yayınevi. 2005.

[27] Maslach J., Jackson S E. The measurement of experienced burnout. Journal of Occupational Behaviour, 2: 99-113, 1981.

[28] Patch A R. Reflection on perfection. American Psychologist, 39: 386-390, 1984.

[29] Philippe F L., Vallerand R J., Lavigne G L. Passion does make a difference in people's lives: a look at well-being in passionate and non-passionate individuals. Applied Psychology: Health and Well-Being; 1(1): 3-22, 2009.

[30] Raedeke T D., Smith A L. Development and preliminary validation of athlete burnout measure. Journal of Sport and Exercise Psychology, 23: 281-306, 2001.

[31] Rice K G., Ashby J S., Slaney R B. Self-esteem as a mediator between perfectionism and depression. A structural Equations Analysis, Journal of Counseling and Development, 1998.

[32] Slade P D., Owens R G. A dual process model of perfectionism based on reinforcement theory. Behavioral Modification, 2: 372-390, 1998.

[33] Şahin M., Koruç Z. Spor ve Egzersiz Psikolojisinin Temelleri (Principles of Sport and Exercise Psychology). Ankara: Nobel Akademik Yayıncılık, 2015.

[34] Tashman L S., Eklund G T., Eklund R. The effect of perceived stress on the relationship between perfectionism and burnout in coaches. Anxiety, Stress, \& Coping, 23:195-212, 2008.

[35] Vallerand R J., Blanchard C M., Mageau G A., Koastner R, Ratelle C., Leonard M., Gagne M., Marsolais J. Les Passions de Lame: On obsessive and harmonious passion. Journal of Personality and Social Psychology, 85: 756-767, 2003.

[36] Vallerand R J., Paquet Y., Philippe F L., Charest J. On the role of passion for work in burnout: a process model. Journal of Personality, 78: 289-312, 2010.

[37] Wang C C., Yang H W. Passion for online shopping: The influence of personality and compulsive buying. Social Behaviour and Personality, 36(5):693-706, 2008.

\footnotetext{
* Some part of this study was produced from Ebru Demirci's master's thesis which was carried out at the Institude of Educational Scince of Mersin University.
} 